УДК 658.011.46

\title{
АНАЛИЗ УСЛОВИЙ ПРОГНОЗИРОВАНИЯ ДЕБИТОРСКОЙ ЗАДОЛЖЕННОСТИ
}

\author{
Дейч Ольга Ивановна \\ кандидат экономических наук, доцент \\ Курилов Сергей Владимирович \\ ФГБОУ ВО Иркутский ГАУ \\ им. А.А. Ежевского
}

\begin{abstract}
Аннотация: В статье рассмотрены вопросы связанные с организацией прогнозирования дебиторской задолженности. Не вызывает сомнений то, что устойчивость финансового положения хозяйствующего субъекта в современных условиях во многом зависит от эффективности управления дебиторской и кредиторской задолженностью. В целях повышения платежеспособности предприятия и управлению расчётами с дебиторами и кредиторами необходимо проводить их анализ, что позволит контролировать состояние расчетов, снижать риск невозврата денежных средств и снижения образования просроченной задолженности.
\end{abstract}

Ключевые слова: Анализ, учет, дебиторская задолженность, структура, оборачиваемость.

\section{ANALYSIS OF THE CONDITIONS FOR FORECASTING ACCOUNTS RECEIVABLE}

\section{Kurilov Sergey Vladimirovich Deitch Olga Ivanovna}

\begin{abstract}
The article deals with issues related to the organization of forecasting accounts receivable. There is no doubt that the stability of the financial position of an economic entity in modern conditions largely depends on the effectiveness of the management of receivables and payables. In order to increase the solvency of the enterprise and manage settlements with debtors and creditors, it is necessary to analyze them, which will allow you to control the state of


settlements, reduce the risk of non-repayment of funds and reduce the formation of overdue debts.

Key words: Analysis, accounting, accounts receivable, structure, turnover.

Значительное влияние на финансовые результаты деятельности предприятия, оказывает состояние дебиторской и кредиторской задолженностей, а также оно является неотъемлемой частью денежных отношений и имеет огромное значение в деятельности любой организации. Размер данных задолженностей может существенным образом влиять на формирование конечных показателей экономической деятельности организации, именно поэтому необходимо создание эффективного управления и анализа дебиторской и кредиторской задолженностей. Это позволит контролировать состояние расчетов с дебиторами и кредиторами, снижать риск невозврата дебиторской задолженности и образования просроченной задолженности, а также определять потребность в дополнительных ресурсах для покрытия задолженности [5].

Увеличение дебиторской задолженности приводит к замедлению оборачиваемости капитала предприятия, снижению его деловой активности, к необходимости прибегать к платным заемным ресурсам для покрытия потребности в денежных средствах, а также к наращиванию кредиторской задолженности. В результате снижается прибыль и рентабельность предприятия, замедляются обороты в экономике страны, растет объем заемных обязательств и неплатежей. Многие авторы считают, что наращивание кредиторской задолженности подрывает финансовую устойчивость предприятия, отрицательно влияет на имидж предприятия должника, снижает его кредитоспособность и его инвестиционную привлекательность [1,4].

Для анализа дебиторской задолженности используются баланс, материалы первичного и аналитического бухгалтерского учета. В процессе анализа изучаются динамика, состав, причины и сроки образования дебиторской задолженности; устанавливается сумма нормальной и просроченной задолженности. На ЗАО «Иркутское» отсутствует просроченная задолженность [3].

Анализ состояния дебиторской задолженности начинают с общей оценки динамики ее объема в целом и в разрезе статей. 
Таблица 1

Оценка состава и структуры дебиторской задолженности ЗАО «Иркутское» за период 2016-2020 гг.

\begin{tabular}{|c|c|c|c|c|c|c|c|c|c|c|c|c|}
\hline \multirow{2}{*}{$\begin{array}{l}\text { Виды } \\
\text { дебиторской } \\
\text { задолжен- } \\
\text { ности }\end{array}$} & \multicolumn{2}{|c|}{2016} & \multicolumn{2}{|c|}{2017} & \multicolumn{2}{|c|}{2018} & \multicolumn{2}{|c|}{2019} & \multicolumn{2}{|c|}{2020} & \multicolumn{2}{|c|}{\begin{tabular}{|c} 
Темп роста \\
2020 г. к \\
2016 г \\
\end{tabular}} \\
\hline & 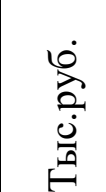 & $\begin{array}{ll}2 & \lambda \\
0 & 0 \\
0 & 0 \\
0 & \vdots\end{array}$ & $\begin{array}{c}\dot{0} \\
\stackrel{0}{0} \\
\dot{0} \\
.\end{array}$ & $\begin{array}{l}z \\
0 \\
0 \\
0\end{array}$ & 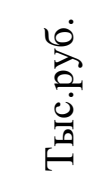 & $\begin{array}{ll}\stackrel{y}{*} & \overrightarrow{0} \\
\circ & 0 \\
\infty & 0\end{array}$ & 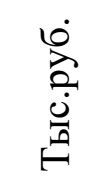 & 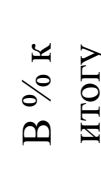 & 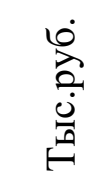 & \begin{tabular}{ll}
\multirow{2}{*}{} & $\overrightarrow{2}$ \\
0 & 0 \\
$\emptyset$ & 0
\end{tabular} & 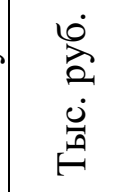 & $\delta^{\circ}$ \\
\hline $\begin{array}{l}\text { Дебиторская } \\
\text { задолжен- } \\
\text { ность, всего, } \\
\text { в том числе }\end{array}$ & $\begin{array}{l}1904 \\
7\end{array}$ & 100 & $\begin{array}{c}1060 \\
5\end{array}$ & 100 & $\begin{array}{c}1297 \\
0\end{array}$ & 100 & $\begin{array}{c}1331 \\
0\end{array}$ & 100 & $\begin{array}{c}1346 \\
1\end{array}$ & 100 & -5586 & 70,67 \\
\hline $\begin{array}{l}\text { Расчеты с } \\
\text { покупателя- } \\
\text { ми и } \\
\text { заказчиками } \\
\text { (счет 62) }\end{array}$ & 1375 & 7,22 & 880 & 8,30 & 1491 & 11,50 & 1792 & 13,46 & 2846 & 21,14 & 1471 & $\begin{array}{c}206,9 \\
8\end{array}$ \\
\hline $\begin{array}{l}\text { С прочими } \\
\text { дебиторами } \\
\text { (счета } 60 \text { и } \\
\text { 76) }\end{array}$ & $\begin{array}{l}1767 \\
2\end{array}$ & 92,78 & 9725 & 91,70 & $\begin{array}{c}1147 \\
9\end{array}$ & 88,50 & $\begin{array}{c}1151 \\
8\end{array}$ & 86,54 & $\begin{array}{c}1061 \\
5\end{array}$ & 78,86 & -7057 & 60,07 \\
\hline
\end{tabular}

В результате оценки состава и структуры дебиторской задолженности предприятия ЗАО «Иркутское» за период 2016-2020 гг. были выявлены следующие изменения: Дебиторская задолженность составила 13461 тыс. руб. в 2020 году, т.е. меньше на 5586 тыс. руб. или на 29,33 \%, чем в 2016 году; расчеты с покупателями и заказчиками возросли на 1471 тыс. руб. или в 2,6 раз и составили 2846 тыс. руб. на отчетный год; расчеты с прочими дебиторами составили в отчетном году 10615 тыс. руб., т.е. наблюдается снижение значения в сравнении с базисным годом на 7057 тыс. руб. или на 60,07\%. Наибольший удельный вес, из входящих в состав статей «Дебиторской задолженности», имеет статья «Расчеты с прочими дебиторами» и составила на 2020 год 78,86\%, что на 13,92\% меньше, чем в базисном году; «Расчеты с покупателями и заказчиками» наоборот имеют наименьший удельный вес и составили на отчетный год $21,14 \%$, что больше на $13,92 \%$, чем в 2016 году. 
Следует отметить, что предприятие не допускает долгосрочную дебиторскую задолженность, т.е. со сроком более года.

Основным показателем эффективности получения дебиторской задолженности является скорость оборачиваемости дебиторской задолженности. Для оценки оборачиваемости дебиторской задолженности используется группа показателей: коэффициент оборачиваемости дебиторской задолженности, период погашения дебиторской задолженности, доля дебиторской задолженности в общем объеме оборотных активов, а также сумма высвобожденных или привлеченных средств [2].

Таблица 2

Оценка оборачиваемости дебиторской задолженности ЗАО «Иркутское» за период 2016-2020 гг.

\begin{tabular}{|l|c|c|c|c|c|c|}
\hline Показатель & 2016 & 2017 & 2018 & 2019 & 2020 & $\begin{array}{c}\text { Изменения } \\
2020 \text {. к } \\
2016 \text {. (+,-) }\end{array}$ \\
\hline $\begin{array}{l}\text { Выручка (нетто) от продажи } \\
\text { продукции, тыс. руб. }\end{array}$ & 105385 & 117725 & 123434 & 121156 & 138999 & 33614 \\
\hline $\begin{array}{l}\text { Средняя дебиторская } \\
\text { задолженность, тыс. руб. }\end{array}$ & 15669 & 14826 & 11787,5 & 13140 & 13385,5 & $-2283,5$ \\
\hline $\begin{array}{l}\text { Среднегодовая стоимость } \\
\text { оборотных активов, тыс. руб. }\end{array}$ & 131146 & 125297 & 106471 & 95879 & 106758,5 & $-24387,5$ \\
\hline Число дней & 360 & 360 & 360 & 360 & 360 & 0 \\
\hline $\begin{array}{l}\text { Период погашения дебиторской } \\
\text { задолженности, дней }\end{array}$ & 54 & 45 & 34 & 39 & 35 & -19 \\
\hline $\begin{array}{l}\text { Коэффициент оборачиваемости } \\
\text { дебиторской задолженности, } \\
\text { раз }\end{array}$ & 6,73 & 7,94 & 10,47 & 9,22 & 10,38 & 3,66 \\
\hline $\begin{array}{l}\text { Доля дебиторской } \\
\text { задолженности в общем объеме } \\
\text { текущих активов,\% }\end{array}$ & 14,83 & 8,68 & 14,29 & 13,18 & 11,96 & $-2,87$ \\
\hline $\begin{array}{l}\text { Сумма высвобожденных (-) или } \\
\text { привлеченных (+) средств в } \\
\text { результате изменения } \\
\text { оборачиваемости дебиторской } \\
\text { задолженности }\end{array}$ & $-1334,48$ & 397,24 & 867,86 & $-421,1$ & 449,39 & $-885,09$ \\
\hline
\end{tabular}

Оценка оборачиваемости дебиторской задолженности предприятия ЗАО «Иркутское» за период 2016-2020 гг. показала: выручка от продажи 
продукции в отчетном периоде составила 138999 тыс. руб., что больше на 33614 тыс. руб., чем в базисном периоде; в 2020 году наблюдается уменьшение средней дебиторской задолженности на 2283,5 тыс. руб. и составила 13385,5 тыс. руб.; среднегодовая стоимость оборотных активов в отчетном году сократилась на 24387,5 тыс. руб. и составила 106758,5 тыс. руб.; период погашения дебиторской задолженности заметно снизился за исследуемый период и составил 35 дней на отчетный период; коэффициент оборачиваемости дебиторской задолженности в отчетном году возрос на 3,66 раза и составил 10,38 раз; доля дебиторской задолженности в общем объеме текущих активов в отчетном периоде составила $11,96 \%$, т.е. сократилась на $2,87 \%$ по сравнению с базисным периодом. Сумма привлеченных средств в результате изменения оборачиваемости дебиторской задолженности составила 449,38 тыс. руб. в 2020 году, т.е. больше на 885,09 тыс. руб. в сравнении с базисным годом.

Проанализировав некоторые показатели, мы выяснили, что наибольший удельный вес составляет сумма по счету 62 «Расчеты с покупателями и заказчиками». Также было выявлено, что в состав статьи «Расчеты с прочими дебиторами» входят расчеты с поставщиками которые имеют наибольшее удельное значение примерно $1 / 4$ от всей суммы.

Оценка оборачиваемости показала, что за исследуемый промежуток времени период погашения дебиторской задолженности заметно снизился и составил 35 дней на 2020 год (см. рисунок 1), оборачиваемость задолженности возросла, на 3,66 раза быстрее, что говорит о том, что предприятие получает оплату за реализованную готовую продукцию быстрее, а сумма привлеченных средств на 2020 год составила 449,38 тыс. руб.

На основании выше изложенного, данную информацию можно представить в виде диаграммы. (Рис. 1) 


\section{Период погашения задолженности}

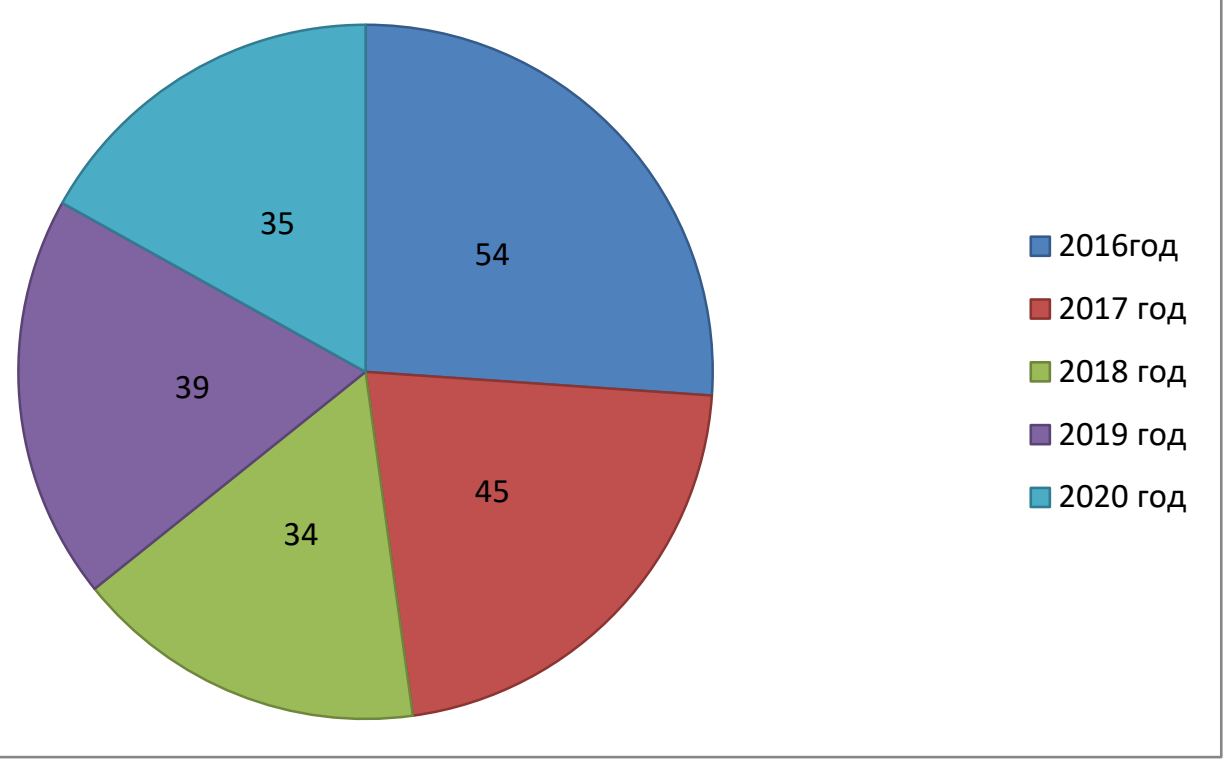

Рис. 1. Период погашения дебиторской задолженности

Как мы видим, наибольшее количество дней оборота задолженности было в 2016 году - 54 дня, наименьшее - в 2018 году - 34 дня, т.е. за 34 дня происходит инкассация дебиторской задолженности. Другими словами, это период времени, который проходит с момента продажи до момента . получения оплаты.

Большое значение имеет правильное отражение в бухгалтерских документах дебиторской и кредиторской задолженностей, поскольку суммы балансовых остатков по данным видам задолженностей, а также периоды оборота каждой из них, непосредственно влияют на объективность оценки платёжеспособности предприятия.

\section{Список литературы}

1. Балсуханова Р.М., Дейч В.Ю. Проблемы бухгалтерского учета расчетов с покупателями и заказчиками // Интеграционные взаимодействия молодых ученых в развитии аграрной науки. Ижевск, 2020. 3 Т С. 47-50.

2. Дейч В.Ю. Проблемы создания информационной базы для анализа бухгалтерского баланса предприятия // Теория и практика современной аграрной науки. - 2020. - С. 139-142. 
3. Ивашкевич В.Б., Семенова И.М. Учет и анализ дебиторской и кредиторской задолженности. - М.: Изд-во «Бухгалтерский учет», 2014, с. 192

4. Колпакова Г. М. Как управлять дебиторской задолженностью. // М.: Финансы и статистика. - 2013, с. 29

5. Кулешова А.И., Дейч О.И. Соотношение дебиторской и кредиторской задолженности // Современные проблемы и перспективы развития агропромышленного комплекса региона. - 2019. - С. 323-326. 